\title{
Combati um bom combate, terminei a corrida, mantive a fé
}

Nathalie da Costa Nascimento ${ }^{1}$, Miriam Cabrera Corvelo Delboni ${ }^{2}$

1. Universidade Federal de Santa Maria, Santa Maria/RS, Brasil.

\begin{abstract}
Resumo
Cuidados paliativos são fornecidos por uma equipe multiprofissional com o fim de promover a qualidade de vida de sujeitos e familiares que enfrentam doenças que ameaçam a continuidade da vida. Como parte dessa equipe, os terapeutas ocupacionais desenvolvem suas ações visando produzir sentidos e sustentar a motivação dos sujeitos. Tomando como base o referencial teórico sobre assistência paliativa, terapia ocupacional e bioética, este artigo relata uma experiência de cuidado de um sujeito em cuidados paliativos em contexto hospitalar. O objetivo é promover a terapia ocupacional como parte importante dos cuidados paliativos oncológicos, tendo em vista que, num contexto de dificuldades e limitações causadas pela doença avançada, as intervenções relatadas se mostraram eficazes. $O$ sujeito do cuidado pôde encontrar um caminho que conferiu sentido a sua história de vida.
\end{abstract}

Palavras-chave: Terapia ocupacional. Cuidados paliativos. Atividades cotidianas.

\section{Resumen}

Peleé la buena batalla, terminé la carrera y mantuve la fe

Los cuidados paliativos son ofrecidos por un equipo multiprofesional con el objetivo de promover la calidad de vida de los sujetos y sus familias que se enfrentan a enfermedades que amenazan la continuidad de la vida. Como parte de este equipo, los terapeutas ocupacionales desarrollan sus acciones con el objetivo de producir sentidos y mantener la motivación de los sujetos. Con base en el marco teórico sobre asistencia paliativa, terapia ocupacional y bioética, este artículo relata una experiencia de cuidado de un sujeto en cuidados paliativos en un contexto hospitalario. El objetivo es promover la terapia ocupacional como una parte importante de los cuidados paliativos oncológicos, teniendo en vista que, en un contexto de dificultades y limitaciones causadas por la enfermedad avanzada, las intervenciones relatadas demostraron ser eficaces. El sujeto del cuidado pudo encontrar un camino que aportó sentido a su historia de vida.

Palabras clave: Terapia ocupacional. Cuidados paliativos. Actividades cotidianas.

\section{Abstract}

\section{I fought the good fight. I finished the race. I kept the faith}

Palliative care is given by a multiprofessional team to promote the quality of life of patients and their family when facing diseases that threaten the continuity of life. As a part of these teams, occupational therapists develop their actions aiming at the production of meanings and sustaining the lives of patients. From literature on palliative care, occupational therapy and bioethics as the theoretical framework, this article reports the care experience of a patient under palliative care in a hospital context. The objective is to promote occupational therapy as a crucial part of palliative care for cancer patients, considering that, in a context of hardships and limitations caused by advanced stages of this disease, the reported interventions were effective. The patient was able to find a path that provided meaning to their life story.

Keywords: Occupational therapy. Palliative care. Activities of daily living. 
Os cuidados paliativos são fornecidos por uma equipe multiprofissional que busca promover a qualidade de vida de pacientes, familiares e cuidadores que enfrentam doenças que ameaçam a continuidade da vida. Esses cuidados são um componente essencial da atenção integral e devem fazer parte do sistema de saúde como política pública. Para que o sofrimento do enfermo seja aliviado, são necessárias a identificação precoce, a avaliação e o tratamento de sintomas e dificuldades físicas, psicossociais e espirituais ${ }^{1-3}$.

O terapeuta ocupacional compõe a equipe multiprofissional e é qualificado para identificar o que os sujeitos reconhecem como necessidades cotidianas relacionadas ao adoecimento. Durante a formação, os princípios da bioética são abordados em interface com a terapia ocupacional. Idealmente, esses princípios são internalizados pelos terapeutas a fim de desenvolver ações de modo singular e individualizado, visando produzir sentidos e sustentar a vida de seus pacientes ${ }^{4-6}$.

No entanto, embora a formação aborde aspectos referentes à bioética, estudos apontam atuação insuficiente de terapeutas ocupacionais em cuidados paliativos oncológicos e despreparo dos profissionais ao lidar com a morte ${ }^{7-9}$. Com o intuito de contribuir para a produção de conhecimento sobre o tema, o presente artigo relata experiência de cuidado de um sujeito em cuidados paliativos oncológicos a partir do aporte conceitual da bioética.

\section{Método}

$\mathrm{O}$ artigo traz relato de experiência com reflexões pautadas no referencial teórico dos cuidados paliativos em interface com a terapia ocupacional e a bioética. Eli (nome fictício) era um jovem de 21 anos, com leucemia em estágio avançado, que viveu seus últimos dias no hospital. O material que deu origem ao artigo é formado por anotações das autoras e registros de atendimentos terapêuticos ocupacionais no sistema eletrônico do hospital universitário onde o paciente estava internado. Os dados são dos meses de agosto e setembro de 2017. O relato de caso foi autorizado mediante esclarecimentos acerca de seus objetivos e assinatura pelo sujeito e seu progenitor de termo de consentimento livre e esclarecido, documento elaborado e padronizado pela Gerência de Ensino e Pesquisa do Hospital Universitário de Santa Maria.
O presente artigo inicialmente apresentará o referencial de cuidados paliativos em interface com a terapia ocupacional e a bioética. Depois serão relatadas intervenções e desfecho do caso, com base na literatura. Destaca-se, quanto aos referenciais teóricos, que autores chamam a atenção para o despreparo dos profissionais para lidar com a morte de seus pacientes e a baixa produção bibliográfica sobre o tema, embora esse número esteja aumentando ${ }^{7-9}$. Portanto, produzir conhecimento nesse campo é fundamental, visto que a partir desse conhecimento o trabalho da terapia ocupacional em cuidados paliativos oncológicos pode se expandir.

\section{Resultados: o livro de Eli}

Eli era um jovem de 21 anos que trabalhava como atendente de loja e morava com os pais. Aos 15 anos, Eli teve diagnóstico de leucemia e, desde então, sonhava com a cura. Era católico, usava um escapulário no pescoço e tinha a imagem de Nossa Senhora de Aparecida na cabeceira do leito. O primeiro contato que tivemos com Eli ocorreu quando ele tinha 20 anos. Na ocasião, a leucemia já estava em estágio avançado e tanto ele como seu pai - que o acompanhava nas internações - estavam cientes do prognóstico reservado. Em virtude da progressão da doença, Eli perdeu a visão e, então, a terapeuta ocupacional foi acionada pela equipe da unidade para acompanhamento, possíveis adaptações no mobiliário do quarto e realização das atividades de vida diária.

Eli permanecia no quarto e, desde o primeiro momento, deixou claro que a perda da visão não era um fator limitante em seu cotidiano, pois mantinha a lembrança de onde estavam os móveis e seus pertences, conseguindo desempenhar as atividades cotidianas de modo independente. O que o inquietava (e também o fazia viver) era que sua namorada estava grávida, com seis meses de gestação, e ele se mostrava preocupado com os cuidados à filha quando ela nascesse.

Ao longo de um mês, a terapeuta ocupacional realizou 15 atendimentos, nos quais foram propostas atividades que tinham por objetivo pensar em estratégias de cuidado com a filha. O objetivo era estimular o envolvimento e resgate de atividades significativas durante o período de hospitalização, pois Eli não saía do quarto e passava a maior parte do tempo no leito. 
Em vista disso, alguns marcos do desenvolvimento neuropsicomotor infantil foram trabalhados. Eli foi informado, por exemplo, de que a filha, mesmo na barriga da mãe, já conseguia ouvir e reconhecer sua voz, o que o deixou muito empolgado. A namorada não costumava ir ao hospital, a pedido do próprio Eli, que compreendia sua situação de saúde e não queria deixá-la apreensiva. No entanto, o casal conversava diariamente pelo celular, e Eli passou a pedir à namorada que colocasse o celular na barriga para que ele conversasse com a filha.

Durante a internação, a equipe da unidade organizou um chá de bebê em que estiveram presentes a namorada, a mãe, a sogra e outros familiares de Eli. $\mathrm{Na}$ ocasião, a terapeuta ocupacional, além de participar como convidada, acompanhou o paciente, descrevendo como o espaço em que ocorria o chá de bebê estava organizado e decorado e como eram as lembrancinhas. Um detalhe interessante é que, após a descrição do ambiente feita pela terapeuta ocupacional, a namorada de Eli também passou a descrever os presentes à medida que os abria.

Eli sempre teve muita fé na cura, mas sabia da gravidade de sua doença. À medida que o tempo passava, seu corpo dava sinais mais contundentes de proximidade da morte. Conforme a doença avançava e a cura não era mais possível, os sintomas se agravavam, e muitas vezes os atendimentos terapêuticos ocupacionais se resumiam à escuta qualificada. Quando a terapeuta chegava, Eli, que não gostava de silêncio, a convidava para se sentar no leito, ao seu lado, e contava histórias de vida, momentos agradáveis e planos para o futuro, com o nascimento de sua única filha. Mas o paciente também expressava seus medos... E se ele partisse antes que a filha nascesse?

Pensando nessa possibilidade e considerando o vínculo terapêutico estabelecido, a terapeuta passou a introduzir atividades de reminiscência nos atendimentos. Eli escolheu construir o que chamou de "cápsula do tempo", um projeto que levou cinco atendimentos para ser concluído. Mas o que era significativo para ser colocado nessa cápsula do tempo destinada à filha?

Os primeiros itens escolhidos foram músicas e fotos com a namorada. Essa atividade reverberou em outros momentos do cotidiano de Eli, para além dos atendimentos terapêuticos ocupacionais, pois o motivou a procurar e escolher fotos e músicas que mais the agradavam durante o dia. Embora não enxergasse mais, Eli se valeu da memória para narrar à terapeuta ocupacional como eram as fotos que queria colocar na cápsula do tempo, publicadas em seu perfil numa rede social. As músicas foram escolhidas a partir da playlist de Eli no celular. Tanto as fotos como as músicas foram salvas em um pen drive e colocadas na cápsula do tempo.

O segundo item escolhido foi uma carta para a filha, elaborada durante um atendimento. Foi sugerido a Eli que gravasse a carta em áudio ou, se se sentisse mais confortável, narrasse o que gostaria de dizer para que a terapeuta escrevesse. Eli escolheu a segunda opção. Na carta, escrita em primeira pessoa e direcionada à filha, Eli se referia a ele e à namorada como "papai e mãe".

A carta inicia com uma apresentação de Eli e da namorada à filha. Na sequência, ele conta dos presentes que a filha já ganhou, do chá de bebê que teve naquela semana - "sua primeira festinha" - e do quanto ele e a namorada são pessoas que lutaram por seus sonhos e sempre gostaram de ajudar os outros. Na carta, Eli destaca que naquele momento estava hospitalizado, passando por um tratamento de saúde, mas ficaria bem quando a filha chegasse. Em certo momento diz: "O mundo aqui fora não é fácil, mas saiba que a cada novo dia podemos fazer algo para que ele melhore". Por fim, Eli apresenta os familiares e padrinhos de batizado e deseja que a filha seja uma pessoa "honesta e sincera, e que nunca meça esforços para ajudar as pessoas que a cercam, sejam eles familiares ou não".

A carta foi assinada por Eli, e ao final consta que foi escrita com o auxílio da terapeuta ocupacional. Posteriormente a carta foi digitada, novamente assinada por Eli e colocada na cápsula do tempo (um bauzinho de madeira fechado a chave). No dia em que foi entregue e lida a versão final, Eli se lembrou de uma frase que ouviu no filme "O livro de Eli" e que gostaria de acrescentar à carta. A frase era: "Combati um bom combate. Terminei a corrida. Mantive a fé". Eli comunicou aos familiares que a cápsula do tempo ficaria com eles e seria entregue à filha no seu aniversário de 15 anos. Eli morreu dias depois de terminar sua cápsula.

\section{Discussão}

Os cuidados paliativos surgiram na década de 1960, no Reino Unido, com o trabalho de 
Cicely Saunders dedicado a sujeitos com câncer em estágio avançado. Saunders, que tinha formação humanista e tornou-se médica, estudou a dor oncológica e criou o conceito de "dor total", o qual afirma que uma pessoa sofre, além de impactos físicos, com as implicações emocionais, sociais e espirituais de doenças ameaçadoras da vida. Em 1967, Cicely Saunders fundou em Londres o St. Christopher's Hospice, um marco na consolidação e divulgação dos cuidados paliativos no mundo ${ }^{1,2}$.

Além da assistência aos doentes, a proposta do St. Christopher's Hospice incluía práticas de ensino e pesquisa. A instituição recebia profissionais de vários países, principalmente dos Estados Unidos e Canadá, que levavam a prática dos cuidados paliativos para seus locais de origem. Em meados da década de 1970, a assistência paliativa foi difundida nos EUA por Elizabeth Kübler-Ross, e um hospice foi fundado no país. A partir de então esse tipo especializado de cuidado se espalhou por diversos países ${ }^{1,10}$.

Em 1990, a partir de uma reunião de especialistas em câncer e assistência paliativa de vários países, a Organização Mundial da Saúde (OMS) publicou sua primeira definição de cuidados paliativos, reconhecendo-os e recomendando-os como prioridade de saúde. Em 2002, o conceito foi revisto e ampliado para outras doenças crônicas, como aids, doenças cardíacas, renais, degenerativas e neurológicas. Dois anos depois, um novo documento foi lançado pela OMS, Palliative care: the solid facts, que recomendava a inclusão dos cuidados paliativos no tratamento de todas as doenças crônicas ${ }^{1,11}$.

O Ministério da Saúde (MS) vem consolidando os cuidados paliativos formalmente no sistema de saúde do país por meio de portarias e documentos do próprio ministério e da Agência Nacional de Vigilância Sanitária ${ }^{12}$. A Portaria $874 \mathrm{GM} / \mathrm{MS}$, de 16 de maio de 2013, institui a Política Nacional para a Prevenção e Controle do Câncer na Rede de Atenção à Saúde das Pessoas com Doenças Crônicas no âmbito do Sistema Único de Saúde. Destaca-se nessa portaria o artigo 13, que aponta: Fazem parte do cuidado integral a prevenção, a detecção precoce, o diagnóstico, o tratamento e os cuidados paliativos, que devem ser oferecidos de forma oportuna, permitindo a continuidade do cuidado ${ }^{13}$.

O Instituto Nacional de Câncer (Inca) dispõe que o tratamento ativo e os cuidados paliativos não são mutuamente excludentes. A instituição propõe que os cuidados paliativos sejam aplicados no curso da doença, em conjunto com o tratamento oncológico ativo, e aumentem gradualmente se a cura não for mais possível. Embora avanços terapêuticos tenham sido alcançados nos últimos anos, a taxa de sobrevida aponta que aproximadamente um terço das pessoas com câncer o vivenciarão sem perspectiva de cura. É preciso aliviar o sofrimento e reduzir os conflitos emocionais desses pacientes e familiares, proporcionando conforto físico, psíquico, espiritual e social ${ }^{6,14}$.

Componente essencial da assistência integral à saúde, cuidados paliativos são um direito humano básico, sobretudo ao final da vida. Eles devem ser ofertados por equipes multiprofissionais e integrar o sistema de saúde como política pública, nos diferentes níveis de atenção ${ }^{2,3}$. Tendo como base a definição da OMS, Byock ${ }^{15}$ destaca os princípios dos cuidados paliativos:

A OMS recomenda que o tratamento paliativo seja iniciado o mais precocemente possível, de preferência junto com o tratamento curativo, empreendendo todos os esforços necessários para compreender e controlar os sintomas. Essa abordagem pode prevenir e aliviar o sofrimento decorrente de desconfortos físicos, psicossociais e espirituais causados pela doença e a proximidade da morte ${ }^{3}$.

O conceito de cuidados paliativos se ampliou e pode ser adaptado a diferentes realidades regionais, aos recursos disponíveis nos serviços de atenção e ao perfil epidemiológico da população atendida. A assistência paliativa, por entender que o sujeito é composto por muitas dimensões, corrobora a Política Nacional de Humanização (PNH), lançada em 2003, que tem como princípios norteadores a valorização da dimensão subjetiva e social e o fortalecimento do trabalho multiprofissional em equipe ${ }^{15}$.

\section{Terapia ocupacional, cuidados paliativos e bioética}

A formação dos terapeutas ocupacionais busca capacitá-los para o trabalho multiprofissional em equipe, qualificando-os para identificar necessidades relativas à ocupação de cada sujeito e relacioná-las ao processo de vida e adoecimento. Dessa forma, esses profissionais prestam assistência individualizada e singular com o intuito de sustentar a vida e produzir sentidos para seus pacientes ${ }^{5,6}$. 
Nos cuidados paliativos, o terapeuta ocupacional busca atividades significativas, que envolvam o sujeito e seus familiares, criando possibilidades de comunicação e exercício da criatividade e enriquecendo o cotidiano com estímulos sensoriais e cognitivos. Também é papel do terapeuta ocupacional dar orientações sobre medidas de conforto e controle de sintomas, treinar o paciente para a realização de atividades de vida diária - otimizando a funcionalidade para autonomia e independência pelo máximo de tempo possível - e fornecer apoio e escuta a familiares e cuidadores, independentemente da fase da doença ${ }^{5,16}$. A profissão é ancorada na ciência ocupacional, que tem por princípio a ideia de que todo ser humano, vivendo em seu contexto social, cultural e político, tem direito à justiça ocupacional, isto é, a participar da sociedade por meio da ocupação que lhe é significativa e de maior relevância ${ }^{4,17,18}$.

Terapeutas ocupacionais devem avaliar seus pacientes tendo-os como protagonistas dessas avaliações, respeitando-os e valorizando sua autonomia, a fim de construir em conjunto um plano terapêutico que considere as necessidades centradas nos desejos ocupacionais de cada sujeito. Isso significa que respeito, autonomia e ética profissional são princípios inseridos na formação do terapeuta ocupacional. Tais princípios não são enfatizados apenas nas disciplinas ligadas à bioética, mas fazem parte de todas as esferas de conhecimento e atuação profissional ${ }^{4,11}$.

Para terapeutas ocupacionais, a autonomia é um conceito fundamental. Assim, a relação estabelecida no processo terapêutico deve se centrar no paciente, fortalecendo o seu protagonismo. Como apontam Ballarin e colaboradores ${ }^{19}$, ter a autonomia como princípio implica compreender o sujeito atendido, considerar sua cultura, contexto, ideias, valores e crenças, e respeitar sua liberdade de escolha no que tange ao próprio tratamento.

Segundo Armitage e Crowther ${ }^{20}$, para atender pacientes terminais, terapeutas ocupacionais devem ter a capacidade de observar, escutar e trabalhar com cada sujeito individualmente, identificando papéis e valores ocupacionais outrora desempenhados. O objetivo da atuação é melhorar a qualidade de vida desses pacientes, preservando sua autonomia na tomada de decisão, mesmo no processo de finitude ${ }^{20}$. Desse modo, tendo em vista que o objetivo da teoria ocupacional é garantir a autonomia e promover a justiça ocupacional, seu encontro com os princípios da bioética (autonomia, beneficência, não maleficência e justiça) é bastante fértil ${ }^{4,11}$.

\section{Acápsula do tempo de Eli}

Desde o primeiro momento Eli deixou claro que a perda da visão não era um fator limitante para desempenhar atividades cotidianas relacionadas ao autocuidado (higiene pessoal, vestir-se, alimentar-se e mobilidade). $O$ foco de sua inquietação eram os cuidados com a filha, quando ela nascesse. Assim, embora as intervenções da terapeuta ocupacional tenham se voltado às reminiscências, isso não limitou as possibilidades de atuação nos cuidados paliativos.

Sujeitos em fase final de vida experimentam situações comuns, mas expressas de diferentes formas, de acordo com cada contexto pessoal e sociocultural. Essa variedade de experiências gera uma série de desafios aos terapeutas ocupacionais. Um desses desafios é aceitar que alguns projetos acordados com o paciente podem ser frustrados por inúmeras variáveis sobre as quais não se tem controle. Para dar um exemplo, pode ser que o paciente, em razão do uso de medicamentos ou da própria evolução do quadro clínico, mostre debilidade ou indisposição para realizar o projeto idealizado. Nesse momento, é importante que o profissional compreenda as complexidades que envolvem a finitude da vida e se lembre do princípio da não maleficência ${ }^{4,11}$.

Com a construção da cápsula do tempo, a terapeuta ocupacional pôde abordar abertamente os planos de Eli e compreender seus desejos. Além disso, o pai do paciente sempre acompanhou os atendimentos, estando a par do que era trabaIhado. Embora não intervisse ou participasse abertamente da construção da cápsula, ele observava tudo. Nessa situação, pode ser que a elaboração do luto era antecipada, ao mesmo tempo em que o pai ficava ciente de todos os planos do filho.

O paciente terminal nem sempre tem a possibilidade de resolver suas pendências, sejam financeiras, familiares ou emocionais. Daí a importância da estratégia adotada, que, por meio do fazer humano, criou possibilidades de comunicação. Havia um propósito no que estava sendo feito, 
e tanto Eli como o pai tiveram a oportunidade de compartilhar lembranças e realizar seus últimos desejos, buscando tornar mais ameno o momento que se aproximava: a inevitável partida.

Outra reflexão bioética que envolve a prática cotidiana dos terapeutas ocupacionais refere-se à autonomia. No caso de Eli, foi possível trabaIhar com sua autonomia, desejos e escolhas pelo forte vínculo terapêutico que se criou. Contudo, muitas vezes, os profissionais podem se frustrar com a recusa do atendimento. Nesse caso, os terapeutas devem tentar se aproximar do sujeito e, paulatinamente, estabelecer vínculos, fortalecendo a confiança para a escuta e a construção conjunta de projetos. Persistindo a recusa e esgotadas as tentativas do profissional, a liberdade de escolha do paciente deve ser respeitada ${ }^{4,11}$.

Pacientes em cuidados paliativos tendem a refletir sobre o uso do tempo, sobre a forma como lidaram com suas relações afetivas durante a vida, sobre a interrupção de seus papéis ocupacionais e sobre privações provenientes dos longos períodos de internação e da debilidade física ${ }^{21}$. Por isso, tendo em vista que não há cura, não há garantia, há fragilidade, desamparo e solidão ${ }^{22}$, a escuta é fundamental no cuidado de um sujeito com doença em estágio avançado.

Em atendimentos hospitalares, ambulatoriais ou em domicílio, o terapeuta ocupacional aplica estratégias para evitar que o sujeito se enclausure na impossibilidade. Por meio da atividade humana, o profissional busca brechas de vida, potência e criação, descobrindo ligações entre passado, presente e futuro, pois, até o último momento, a vida não pode perder seu sentido. Essa intervenção é fundamental, pois, com base na história, desejos, significados e necessidades do paciente, o terapeuta pode ampliar as possibilidades do fazer cotidiano, compreendendo as atividades como fontes de experiência e estimulando a criação de projetos de vida, fechamento e despedida ${ }^{6,16,21}$.

Devido à complexidade do atendimento integral aos sujeitos em cuidados paliativos, o trabalho de diferentes profissionais é necessário. Por isso, embora o presente artigo apresente exclusivamente as contribuições da terapia ocupacional, destaca-se que Eli foi cuidado por toda uma equipe multiprofissional. Somente o trabalho integrado é capaz de construir um caminho significativo ao paciente, que considere sua existência em todos os ciclos, do nascimento à morte ${ }^{6,23}$.

\section{Considerações finais}

As intervenções do atendimento terapêutico ocupacional possibilitaram reflexões e recordações que deram sentido e propósito à vida de Eli até o último momento. A experiência deixou evidente a potência das atividades propostas, que deram resiliência ao paciente para enfrentar aquilo que parece estar além da compreensão humana. Dessa forma, Eli inscreveu sua singularidade no espaço-tempo ao criar um elo entre passado, presente e futuro, perpetuando-se na vida daqueles que tanto amou.

A construção da cápsula do tempo e a escolha dos elementos que a constituíram parece ter sido uma maneira de Eli deixar algo de si no mundo e materializar seu amor. Num primeiro momento, essa construção pode parecer fúnebre, mas é fundamental destacar que os atendimentos, durante todo o projeto, nunca foram tristes. Pelo contrário, os encontros eram marcados por boas lembranças, histórias e esperança. Isso porque, embora tanto Eli e seu pai como a terapeuta ocupacional soubessem que se tratava de uma despedida, naquele momento não se estava falando de doença ou morte, mas sim de vida.

Conclui-se, portanto, que a estratégia adotada permitiu que a terapeuta ocupacional dessa sua contribuição aos cuidados paliativos. Mesmo em um contexto de dificuldades e limitações trazidas pela doença avançada, as intervenções se mostraram eficazes ao apontar um caminho capaz de dar sentido e (re)construir a história de vida de Eli, assim como sugerir projetos para o futuro daqueles que ficaram após sua partida. Tendo claro seu objeto de intervenção (a ocupação humana), a terapeuta pôde identificar dimensões que ultrapassam a condição física (no caso, a deficiência visual e a leucemia).

Quando baseia suas ações em referenciais teóricos interdisciplinares (como a bioética) e centra o cuidado no paciente, o terapeuta ocupacional consegue realizar seu trabalho de acordo com os propósitos da profissão. Solidariedade, respeito, equidade, comprometimento e responsabilidade são conceitos que permeiam a prática de terapeutas que assistem sujeitos em cuidados paliativos. Manter reflexões diárias sobre esses conceitos é essencial para o trabalho desses profissionais. 


\section{Referências}

1. Matsumoto DY. Cuidados paliativos: conceito, fundamentos e princípios. In: Carvalho RT, Parsons HA, editores. Manual de cuidados paliativos ANCP [Internet]. São Paulo: Academia Nacional de Cuidados Paliativos; 2012 [acesso 15 dez 2019]. p. 23-30. Disponível: https://bit.ly/33Qj8rO

2. Gómez-Batiste X, Connor S, Murray S, Krakauer E, Radbruch L, Luyirika et al. Principles, definitions and concepts. In: Gómez-Batiste X, Connor S. Building integrated palliative care programs and services [Internet]. London: WHPCA; 2017 [acesso 20 dez 2019]. p. 45-62. Disponível: https://bit.ly/2RVEYrO

3. Carlo MMR, Kebbe LM, Palm RDCM. Fundamentação e processos da terapia ocupacional em contextos hospitalares e cuidados paliativos. In: Carlo MMRP, Kudo AM. Terapia ocupacional em contextos hospitalares e cuidados paliativos. São Paulo: Payá; 2018. p. 1-32.

4. Kantartziz S, Molineux M. The influence of Western society's construction of a healthy daily life on the conceptual is action of occupation. J Occup Sci [Internet]. 2011 [acesso 13 dez 2019];18(1):62-80. DOI: $10.1080 / 14427591.2011 .566917$

5. Costa APP, Othero MB. Reabilitação em cuidados paliativos. Loures: Lusodidacta; 2014.

6. Cavalcante AC, Maués NCS, Castro GGA. Ocupações e significados em cuidados paliativos oncológicos: o caso de "Nobreza" em seu processo de finitude. Rev Fam, Ciclos Vida Saúde Contexto Soc [Internet]. 2018 [acesso 23 dez 2019];6(1):140-51. DOI: 10.18554/refacs.v6i1.1876

7. Baltazar HMC, Pestana SCC, Santana MRR. Contributo da intervenção da terapia ocupacional nos Cuidados Paliativos. Cad Ter Ocup UFSCar [Internet]. 2016 [acesso 22 dez 2019];24(2):261-73. DOI: 10.4322/ 0104-4931.ctoAO0692

8. Sartori AV, Battistel ALHT. A abordagem da morte na formação de profissionais e acadêmicos da enfermagem, medicina e terapia ocupacional. Cad Ter Ocup UFSCar [Internet]. 2017 [acesso $20 \mathrm{dez}$ 2019];25(3):497-508. DOI: 10.4322/2526-8910.ctoAO0770

9. Peñas-Felizzola OF, Parra-Esquivel El, Gómez-Galindo AM. Terapia ocupacional en oncología: experiencias en prácticas académicas y revisión de literatura. Rev Salud Pública [Internet]. 2018 [acesso 15 dez 2019];20(1):45-52. DOI: 10.15446/rsap.V20n1.62227

10. Du Boulay S. Changing the face of death: the story of Cicely Saunders. $2^{\mathrm{a}}$ ed. Barnstaple: Bright Sea; 2007.

11. Pessini L, Bertachini L. Nuevas perspectivas en cuidados paliativos. Acta Bioeth [Internet]. 2006 [acesso 16 dez 2019];12(2):231-42. DOI: 10.4067/S1726-569X2006000200012

12. Hermes HR, Lamarca ICA. Cuidados paliativos: uma abordagem a partir das categorias profissionais de saúde. Ciênc Saúde Coletiva [Internet]. 2013 [acesso 17 dez 2019];18(9):2577-88. DOI: 10.1590/ S1413-81232013000900012

13. Brasil. Ministério da Saúde. Portaria $n^{\circ} 874$, de 16 de maio de 2013. Institui a Política Nacional para a Prevenção e Controle do Câncer na Rede de Atenção à Saúde das Pessoas com Doenças Crônicas no âmbito do Sistema Único de Saúde (SUS). Diário Oficial da União [Internet]. Brasília, 2013 [acesso 14 dez 2019]. Disponível: https://bit.ly/3hAKXfA

14. Instituto Nacional de Câncer. Câncer: cuidados paliativos [Internet]. Rio de Janeiro: Inca; 2019 [acesso 17 dez 2019]. Disponível: https://bit.ly/3wb3Fyl

15. Brasil. Ministério da Saúde. HumanizaSUS: documento base para gestores e trabalhadores do SUS. $4^{\mathrm{a}}$ ed. Brasília: Editora do Ministério da Saúde; 2010 [acesso 15 maio 2021]. Disponível: https://bit.ly/2RYcj4K

16. Santos WA, Lourenço MLPC, Silva CD, Frizzo HCF. Terapia ocupacional em oncologia pediátrica e cuidados paliativos. In: Carlo MMRP, Kudo AM. Terapia ocupacional em contextos hospitalares e cuidados paliativos. São Paulo: Payá; 2018. p. 145-58.

17. Salles MM, Matsukura TS. Estudo de revisão sistemática sobre o uso do conceito de cotidiano no campo da terapia ocupacional no Brasil. Cad Ter Ocup UFSCar [Internet]. 2013 [acesso 10 dez 2019];21(2):265-73. DOI: $10.4322 /$ cto.2013.028

18. Townsend E, Marval R. Profissionais podem realmente promover justiça ocupacional? Cad Ter Ocup UFSCar [Internet]. 2013 [acesso $10 \mathrm{dez} 2019$ ];21(2):229-42. DOI: 10.4322/cto.2013.025 
19. Ballarin MLG, Delboni MCC, Moreira AB, Castro LCR, Palm RCM. Terapia ocupacional e bioética: aporte para as práticas profissionais na interface com os direitos humanos. In: Sganzerla A, Chemin MRC, Rauli PMF, editores. Bioética nas profissões: ciências da saúde e áreas afins. Curitiba: Editora CRV; 2019. p. 169-87.

20. Armitage K, Crowther L. The role of occupational therapist in palliative care. Eur J Palliat Care. 2000;6:154-7.

21. Othero MB, Ayres JRCM. Resgate biográfico como estratégia de assistência. Rev Ter Ocup Univ São Paulo [Internet]. 2014 [acesso 14 dez 2019];25(1):80-7. DOI: 10.11606/issn.2238-6149.v25i1p80-87

22. Castro-Arantes JM, Lo Bianco AC. Corpo e finitude: a escuta do sofrimento como instrumento de trabalho em instituição oncológica. Ciênc Saúde Coletiva [Internet]. 2013 [acesso 15 dez 2019];18(9):2515-22. p. 2521. DOI: $10.1590 / \mathrm{S1413}-81232013000900005$

23. American Occupational Therapy Association. Occupational therapy practice framework: domain and process (3rd edition). Am J Occup Ther [Internet]. 2015 [acesso 24 dez 2019];26:1-48. DOI: 10.5014/ajot.2014.682006

Nathalie da Costa Nascimento - Mestre - costtanathalie@gmail.com

(D) 0000-0003-4986-6967

Miriam Cabrera Corvelo Delboni - Doutora - miriamdelboni@gmail.com

(D) 0000-0001-5049-4561

Correspondência

Nathalie da Costa Nascimento - Av. Roraima, Prédio $26 \mathrm{C}$

CEP 97105-900. Santa Maria/RS, Brasil.

Participação das autoras

As autoras contribuíram igualmente para o artigo.

Recebido: 27.12.2019

Revisado: 22.4 .2021

Aprovado: 25.4 .2021 